\title{
Identifying Hydrocarbon and Fluorocarbon Surfactants in Specialty Chemical Formulations of Environmental Interest by Fast Atom Bombardment/Mass Spectrometry
}

\author{
Jennifer A. Field*, Melissa Schultz, and Douglas Barofsky
}

\begin{abstract}
Hydrocarbon- and fluorocarbon-based surfactants are used in specialty or 'niche' chemical formulations that are designed for applications such as aircraft deicing and anti-icing, 'spreaders' that increase the effectiveness of pesticide formulations, and for fighting hydrocarbon-fuel fires. The identity of the surfactants in specialty formulations is usually proprietary information. However, this information is needed to design studies that monitor the occurrence and fate of all the components of specialty chemical formulations that enter the environment and pose a risk toward aquatic organisms. Fast atom bombardment/mass spectrometry (FAB/MS), while not a new technique, remains the fastest technique for identifying surfactants in complex mixtures because no sample preparation is required. FAB/MS was applied to samples of an aircraft deicer and anti-icer and aqueous-film-forming-foams (AFFF) for the purpose of identifying the major classes of hydrocarbon and fluorocarbon surfactants. High mass accuracy FAB/MS measurements were made to identify an unknown fluorosurfactant in an AFFF formulation. Rapid identification of surfactants that are released into the environment facilitates the subsequent selection of quantitative analytical methods that can be used to monitor the occurrence and fate of surfactants in the environment.
\end{abstract}

Keywords: Aircraft deicers and anti-icers · Aqueous-film-forming-foams (AFFF) .

Fast atom bombardment/mass spectrometry $\cdot$ Surfactants

\section{Introduction}

Fast atom bombardment mass spectrometry (FAB/MS) is a technique that was developed in the 1980s and that quickly found its niche in the determination of polar molecules that were not amenable to gas-phase techniques [1][2]. During the 1980s and early 1990s several reports on the use of FAB/MS for identifying surface-activeagents (surfactants) in commercial product [3-6] and environmental samples [7-10] appeared in the literature. The majority of

\footnotetext{
${ }^{*}$ Correspondence: Prof. Dr. J.A. Field Department of Environmental and Molecular Toxicology Oregon State University Corvallis, Oregon, U.S.A., 97331

Tel.: +15417372265

Fax: +1541737 0497

E-Mail: Jennifer.Field@orst.edu

http://www.emt.orst.edu/faculty/field.htm
}

reports describe the use of FAB/MS for the qualitative analysis of surfactants while only a limited number of reports describe the quantitative analysis of surfactants by FAB/MS [7][9][11]. With the advent of liquid chromatography/tandem mass spectrometry (LC/MS/MS), many quantitative LC/MS/MS methods have appeared in the literature for the analyses of surfactants [12-16]. However, LC/MS/MS is not the method of choice when qualitative information is needed to initially identify classes of surfactants. Compared to LC/MS/MS, FAB/MS is faster and less complicated. With the publication of a table of characteristic ions acquired under positive ionization mode, Ventura et al. [10] made it possible to quickly identify many classes of commonly-used surfactants that are used in specialty chemical formulations.

For this study, a select number of specialty chemical formulations were analyzed by FAB/MS in order to identify the surfactants in the complex mixtures. The specialty formulations analyzed for this study included deicing and anti-icing fluids and two aqueous film-forming foam (AFFF) formulations. Deicing and anti-icing fluids are used to deice and prevent ice formation on aircraft and typically consist of propylene or ethylene glycol, water, and additives including corrosion inhibitors, polymers, and surfactants [17][18]. Aqueous filmforming foams (AFFF) are complex mixtures of hydrocarbon and fluorocarbon surfactants and other components that are used to extinguish hydrocarbon-fuel fires [19-22]. This study was prompted by the need to identify the surfactants in the formulations in order to select appropriate analytical methods for use in monitoring studies aimed at determining the occurrence and fate of the surfactants in the environment [17][18][23-25]. 


\section{Experimental}

\section{Samples}

A Type I deicer and a Type IV anti-icer formulation were analyzed for this study by FAB/MS in positive ion mode. Two samples of commercial AFFF formulations were obtained from two different manufacturers. A groundwater sample collected from well PW-10 at Tyndall Air Force Base, Florida was analyzed for this study; the groundwater in the vicinity of this well was known to be contaminated by AFFF wastewaters [19][25-27]. The AFFF formulations and groundwater were analyzed by FAB/MS in negative ion mode. All chemical formulations and the groundwater sample were used as received with no pre-treatment prior to $\mathrm{FAB} / \mathrm{MS}$ analysis.

\section{Fast Atom Bombardment Mass Spectrometry}

FAB/MS was performed on a Kratos MS-50TC (Manchester, England) double focusing instrument operated at unit resolution. The samples of interest were mixed on the probe tip with 3-nitrobenzyl alcohol (98\%, Sigma-Aldrich) as matrix. Xenon gas was used to generate the primary ionizing beam from an Ion-Tech gun operated at 7-8 kV. For high mass accuracy measurements with the FAB/MS, polyethylene glycol was used as a reference compound. The ratio of polyethylene glycols was 4:2:1, respectively.

\section{Results and Discussion}

The Type I deicer contained two polyethoxylated surfactants (Fig. 1) as determined by positive ion FAB/MS. Both classes of ethoxylated surfactants are comprised of a series of ethoxylated oligomers. Ethoxylated surfactants exhibit a characteristic difference of $\mathrm{m} / \mathrm{z} 44$, which corresponds to an ethoxylate group (O$\mathrm{CH}_{2} \mathrm{CH}_{2}$ ). The ions that range from $\mathrm{m} / \mathrm{z}$ 533 to 1193 by units of 44 are characteristic of linear decyl $\left(\mathrm{C}_{10}\right)$ alcohol ethoxylates, $\mathrm{C}_{10} \mathrm{H}_{21}\left(\mathrm{OCH}_{2} \mathrm{CH}_{2}\right)_{n} \mathrm{OH}$ where $\mathrm{n}$ ranges from 8 to 23 [10]. Ions that range from $\mathrm{m} / \mathrm{z}$ 473 to 1177 by units of 44 are characteristics of linear lauryl $\left(\mathrm{C}_{12}\right)$ alcohol ethoxylates, $\mathrm{C}_{12} \mathrm{H}_{25}\left(\mathrm{OCH}_{2} \mathrm{CH}_{2}\right)_{\mathrm{n}} \mathrm{OH}$ where $\mathrm{n}$ ranges from 6 to 22 [10].

Characterization of the ethoxylate range by static (e.g. probe analysis) $\mathrm{FAB} / \mathrm{MS}$ is strictly qualitative because analytes of higher surface activity can suppress the response of analytes that are less surface active [7][9]. For this reason, the actual ethoxylate range is likely to be greater than that indicated by the FAB/MS spectrum and

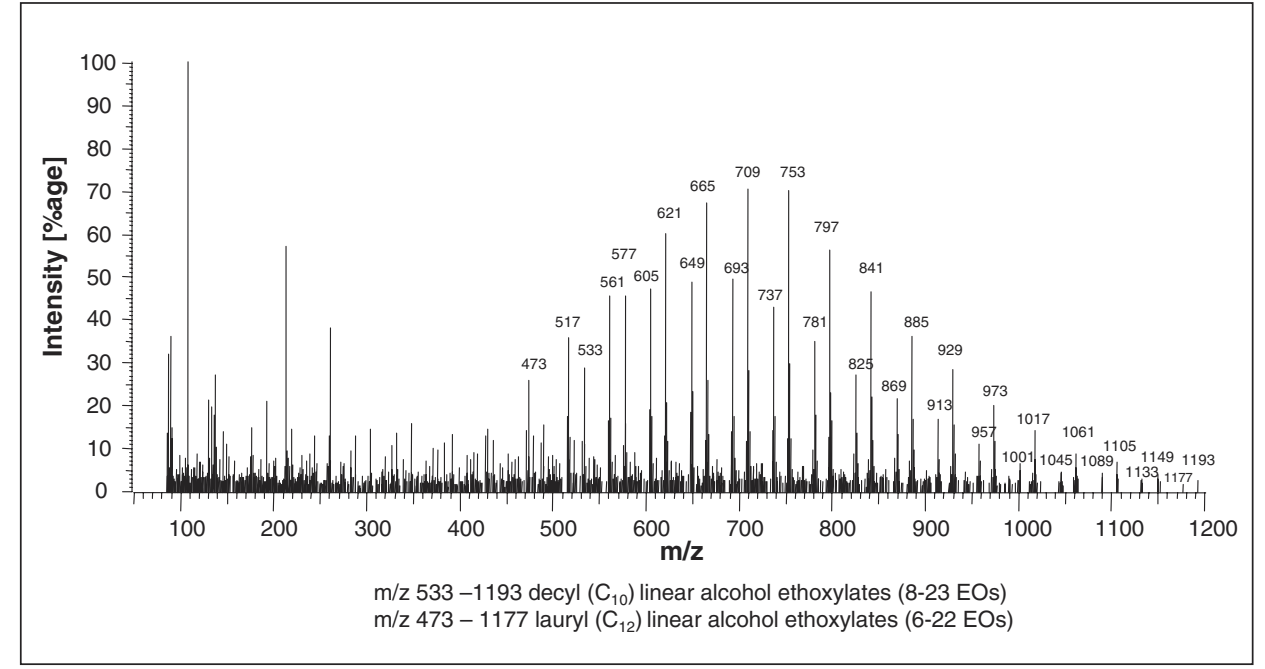

Fig. 1. FAB/MS spectrum of positive ions from a Type I deicer formulation indicating decyl $\left(C_{10}\right)$ and lauryl $\left(\mathrm{C}_{12}\right)$ linear alcohol ethoxylates. the actual relative abundance of the oligomers is probably different as well. However, the range of oligomers determined by FAB/MS can be used to identify appropriate standards and analytical methods needed for quantitative analysis, such as LC/MS/MS.

The Type IV anti-icer is a mixture of three types of surfactants. Octylphenol polyethoxylates, $\mathrm{C}_{8} \mathrm{H}_{17}\left(\mathrm{C}_{6} \mathrm{H}_{4}\right)\left(\mathrm{OCH}_{2} \mathrm{CH}_{2}\right)_{n} \mathrm{OH}$ where $\mathrm{n}$ ranges from 2 to 8 , are indicated by the characteristic ions that differ by $\mathrm{m} / \mathrm{z} 44$ and that range from m/z 317 to 581 (Fig. 2) [10]. The Type IV anti-icer also contains lauryl $\left(\mathrm{C}_{12}\right)$ polyethoxy phosphoric acid esters, $\mathrm{C}_{12} \mathrm{H}_{25}\left(\mathrm{OCH}_{2} \mathrm{CH}_{2}\right)_{n} \mathrm{OPO}_{3} \mathrm{H}$ where $\mathrm{n}$ ranges from 1 to 8 , as indicated by a series of ions from m/z 333 to 641 [10]. A third unidentified class of surfactant is also present but the ions ranging from $\mathrm{m} / \mathrm{z} 391$ to 831 do not correspond to surfactants reported in Ventura et al. [10]. However, the unidentified class is ethoxylated because the difference within the family of ions is $\mathrm{m} / \mathrm{z} 44$.

The first AFFF sample analyzed (AFFF1) gave a very simple negative ion $F A B / M S$ spectrum (Fig. 3). The ions corresponding to $\mathrm{m} / \mathrm{z} 499$ and 399 are characteristic of perfluorooctane sulfonate $\left(\mathrm{C}_{8} \mathrm{~F}_{18} \mathrm{SO}_{3}^{-}\right)$and perfluorohexane sulfonate $\left(\mathrm{C}_{6} \mathrm{~F}_{13} \mathrm{SO}_{3}^{-}\right)$, respectively [5]. The $\mathrm{m} / \mathrm{z} 499$ was observed for a standard of perfluorooctane sulfonate (data not shown). No fragmentation corresponding to products with masses lower than the parent sulfonate anion were observed, which is consistent with the report by Lyon et al. on fluoroalkyl sulfonates [5].

The second AFFF formulation (AFFF2) gave a distinctly different negative ion FAB/MS spectrum (Fig. 4) with two major ions at $\mathrm{m} / \mathrm{z} 586$ and 686 . High mass accuracy measurements gave an $\mathrm{m} / \mathrm{z} 586.04122$ (Fig. 5) that most closely corresponds to an

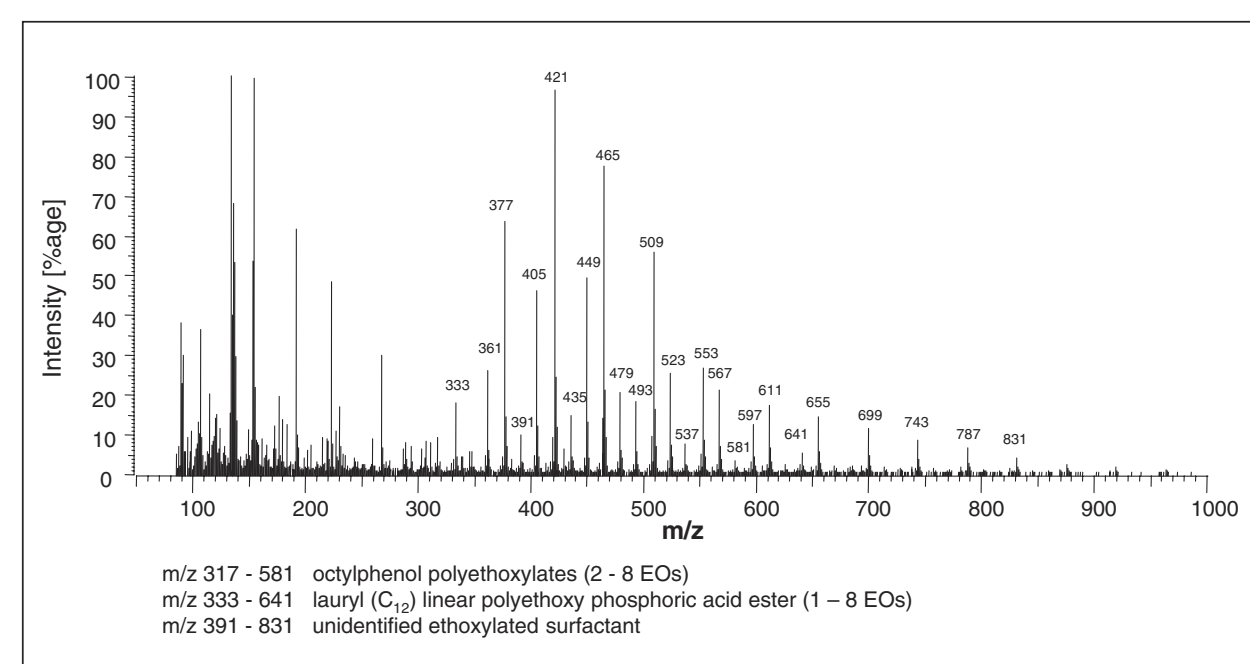

Fig. 2. FAB/MS spectrum of positive ions from a Type IV anti-icer formulation indicating octylphenol polyethoxylates, lauryl $\left(\mathrm{C}_{12}\right)$ linear alcohol ethoxylates, and a third unidentified class of ethoxylated surfactant. 


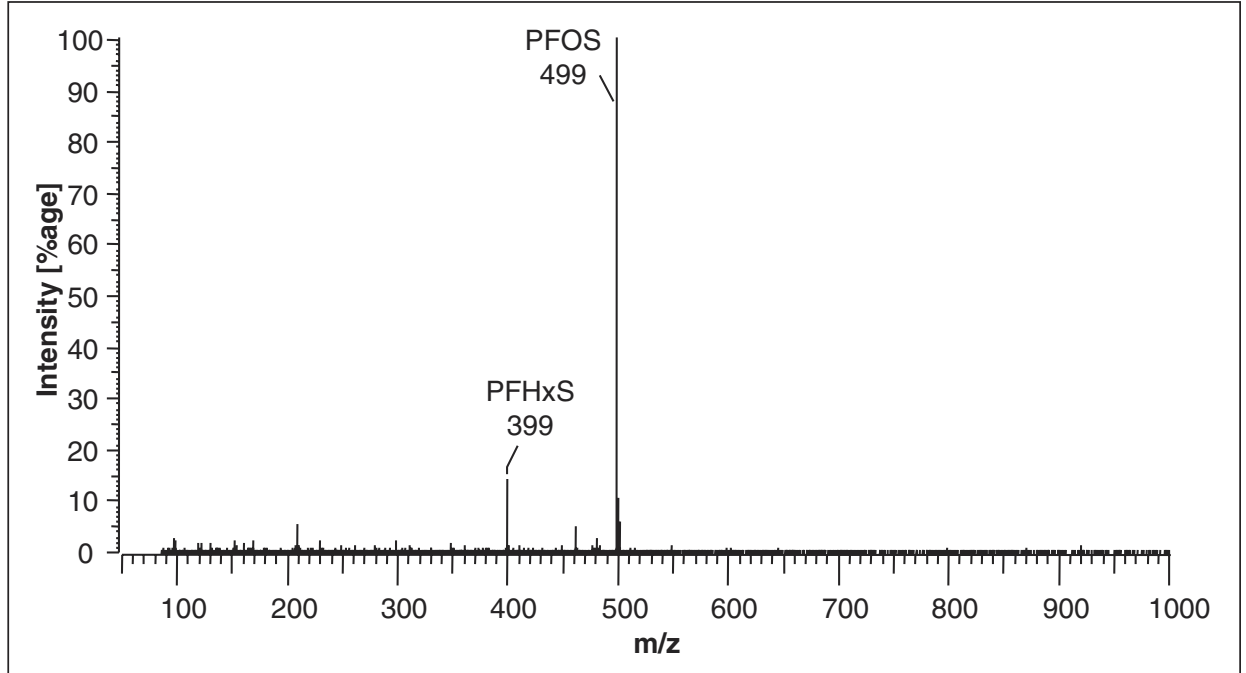

atomic composition of $\mathrm{C}_{15} \mathrm{H}_{17} \mathrm{O}_{4} \mathrm{~F}_{13} \mathrm{NS}_{2}$ which has a mass of $586.03914 \pm 0.00035$. Given the current commercially significant approaches to the fluorosurfactant production [28], the atom arrangement is most likely the fluoroalkylthioamido sulfonate: $\mathrm{C}_{6} \mathrm{~F}_{13} \mathrm{C}_{2} \mathrm{H}_{4} \mathrm{SC}_{2} \mathrm{H}_{4}(\mathrm{C}=\mathrm{O}) \mathrm{NHC}_{2} \mathrm{H}_{2}\left(\mathrm{CH}_{3}\right)_{2} \mathrm{SO}_{3}{ }^{-}$. The high mass accuracy measurement of m/z 686.03607 (Fig. 5) most closely corresponds to the structure of the fluoroalkylthioamido sulfonate $\mathrm{C}_{8} \mathrm{~F}_{17} \mathrm{C}_{2} \mathrm{H}_{4} \mathrm{SC}_{2} \mathrm{H}_{4}(\mathrm{C}=\mathrm{O})$ $\mathrm{NHC}_{2} \mathrm{H}_{2}\left(\mathrm{CH}_{3}\right)_{2} \mathrm{SO}_{3}^{-}$, which has a mass of $686.03276 \pm 0.00033$. The fluorocarbon groups of the fluoroalkylthioamido sulfonates are synthesized by a process known as telomerization that generates only even number of carbons in the fluorocarbon chain. The 100 mass unit difference between $\mathrm{m} / \mathrm{z} 686$ and 586 corresponds to a $-\mathrm{CF}_{2} \mathrm{CF}_{2}-$ group, which is consistent with surfactants produced by telomerization.

The groundwater sample collected from well PW-10, which is located near a firetraining pad at Tyndall Air Force Base, Florida [19], contained perfluorooctane sulfonate (PFOS) and perfluorohexane sulfonate (PFHxS) as indicated by $\mathrm{m} / \mathrm{z} 499$ and 399, respectively (Fig. 6). This finding indicates that AFFF-1 type chemicals were used at this site and is consistent with the independent determination of PFOS and PFHxS by liquid chromatography with tandem mass spectrometry [25-27]. On the other hand, the m/z 586 and 686 observed in AFFF-2 are not seen in the groundwater sample nor were they detected by LC/MS/MS [26]. However, m/z 527 and 427 are observed and correspond to $\mathrm{C}_{6} \mathrm{~F}_{13} \mathrm{CH}_{2} \mathrm{CH}_{2} \mathrm{SO}_{3}^{-}$(6:2 fluorotelomer sulfonate or 6:2 FtS) and $\mathrm{C}_{8} \mathrm{~F}_{17} \mathrm{CH}_{2} \mathrm{CH}_{2} \mathrm{SO}_{3}{ }^{-}$ (8:2 fluorotelomer sulfonate or 8:2 FtS), respectively. Quantitative determinations of the 6:2 and 8:2 fluorotelomer sulfonate were made by LC/MS/MS in confirmation of the FAB/MS data [25-27].

The identification of surfactants in specialty formulations such as deicers, antiicers, and AFFF is important because this information is used to identify or develop specific and sensitive analytical methods
Fig. 3. FAB/MS spectrum of negative ions from the first sample of aqueous film-forming foam (AFFF-1) indicating perfluorooctane sulfonate (PFOS) and perfluorohexane sulfonate (PFHXS). that can then be used to monitor surfactant occurrence and behavior in the environment. Information on surfactant fate, occurrence and behavior is needed to perform risk assessments for all the components of environmental significance in specialty chemical formulations.

Alkylphenol polyethoxylates were identified in the Type IV anti-icer (this study) and in five other deicer and anti-icer formulations [17]. In addition, in previous work we identified nonionic surfactants in an herbicide 'spreader' formulation [24], which is added to herbicide formulations to increase herbicide efficacy [24]. Alkylphenol polyethoxylate surfactants are toxic to aquatic organisms [29][30] and their degradation products, namely alkylphenols, elicit estrogenic responses in aquatic organisms [31-35]. As a result of FAB/MS identifications, subsequent studies were designed to determine the fate of the nonylphenol polyethoxylates using quantitative analytical methods based on high performance liquid chromatography. For example, a monitor-

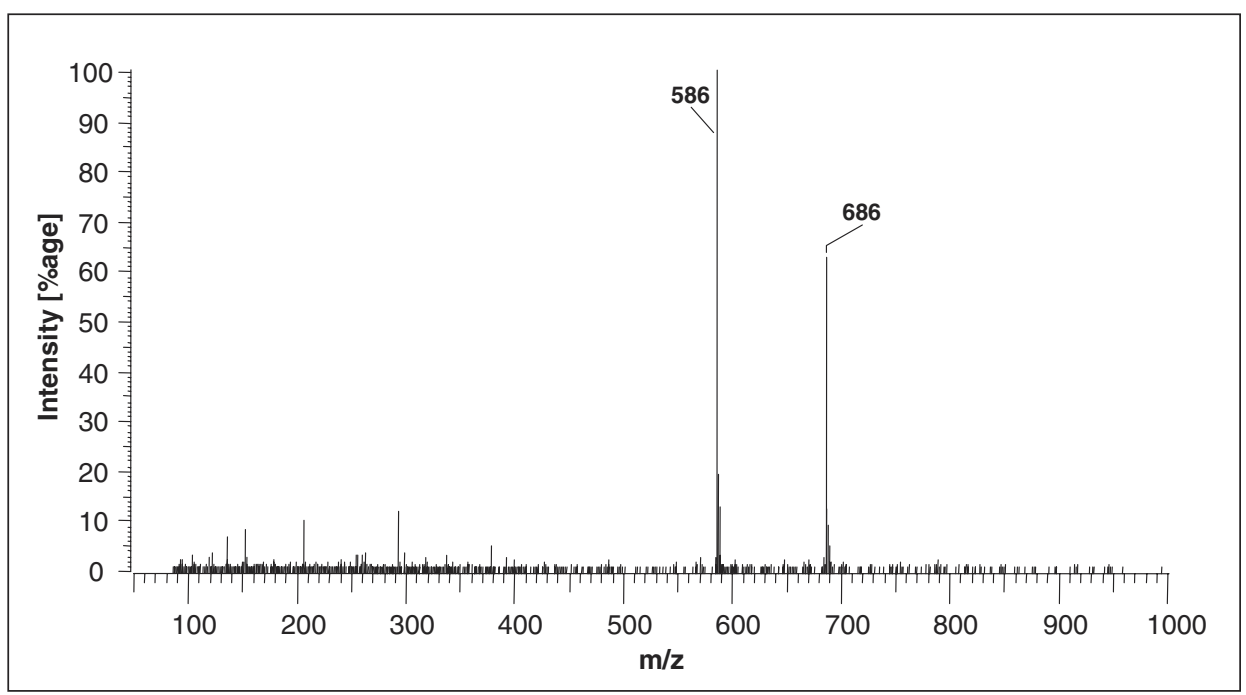

Fig. 4. FAB/MS spectrum of negative ions from the second sample of aqueous filmforming foam (AFFF-2) indicating alkylthioamido sulfonate surfactants. 

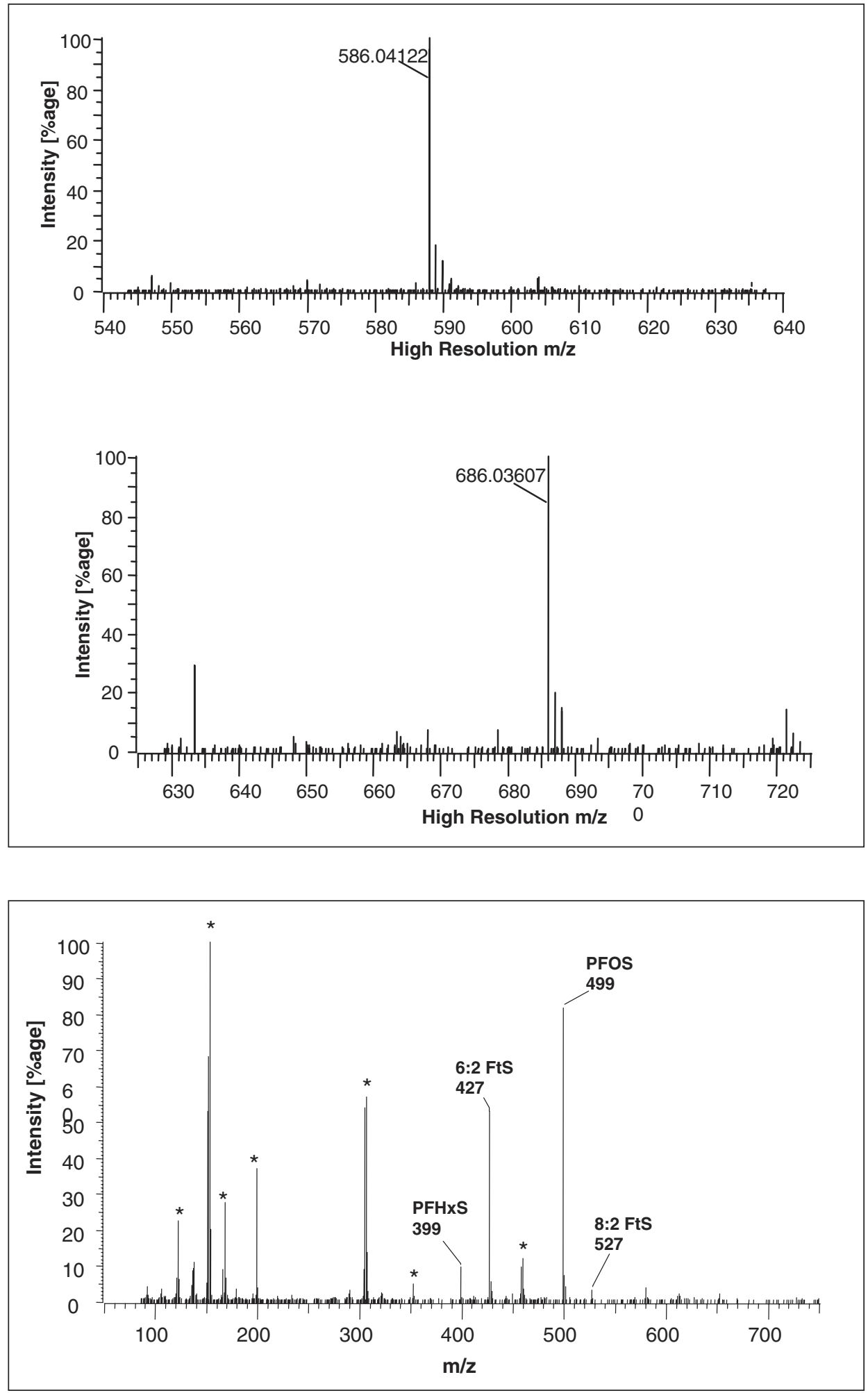

ing study was carried out to determine the fate of nonylphenol polyethoxylates after the pesticide and spreader were applied to an estuary for the purpose of smooth cordgrass control [24] and in airport runoff after applications of aircraft deicer and anti-icer fluids to aircraft [17].

Perfluorooctane sulfonate (PFOS) and perfluorooctanoic acid (PFOA) recently emerged as chemicals of concern [27][36]. Their presence in AFFF formulations led to studies on their occurrence in AFFF-con- taminated groundwater [21][26][37][38]. FAB/MS revealed the identification of the alkylthioamido sulfonate class of flurosurfactants for which no quantitative analytical method has yet been developed. With the detection of fluoroalkylthioamido sulfonates in AFFF but not in groundwater, research is needed to determine the fate of fluoroalkylthioamido sulfonates and the source of fluorotelomer sulfonates.

Fig. 5. High mass accuracy mass spectra for the nominal mass ions of $\mathrm{m} / \mathrm{z} 686$ and 586 for AFFF-2 formulation.

Fig. 6. FAB/MS spectrum of negative ions of a groundwater sample from Tyndall Air Force Base, Florida contaminated by AFFF wastewater with the ions indicated for perfluorooctane sulfonate (PFOS), perfluorohexane sulfonate (PFHxS), 6:2 fluorotelomer sulfonate (6:2 FtS), and the 8:2 fluorotelomer sulfonate (8:2 FtS).

\section{Conclusions}

Fast atom bombardment mass spectrometry remains the most rapid technique for identifying the major classes of surfactants in specialty chemical formulations. Either through deliberate application or by accident during emergencies, the hydrocarbon and fluorocarbon surfactants identified in these mixtures can reach aquatic environments. Identification of surfactants in these mixtures facilitates the selection of 
quantitative analytical methods that can then be applied to support detailed environmental fate studies and risk assessment.

\section{Acknowledgments}

We wish to acknowledge Jeff Morre and the Environmental Health Sciences Center grant NIEHS P30 ES00210 for the FAB/MS analyses and EPA STAR grant R-829025-01 for funding.

Received: July 19, 2003

[1] D.H. Williams, C. Bradley, G. Bojesen, S Santikarn, L.C.E. Taylor, J. Am. Chem. Soc. 1981, 103, 5700 .

[2] R.M. Caprioli, Anal. Chem. 1990, 62 , 477A.

[3] P.A. Lyon, F.W. Crow, K.B. Tomer, M.L. Gross, Anal. Chem. 1984, 56, 2278.

[4] P.A. Lyon, W.L. Stebbings, F.W. Crow, K.B. Tomer, D.L. Lippestreu, M.L. Gross, Anal. Chem. 1984, 56, 8.

[5] P.A. Lyon, K.B. Tomer, M.L. Gross, Anal. Chem. 1985, 57, 2984.

[6] R.M. Facino, M. Carini, P. Minghetti, G. Moneti, E. Arlandini, S. Melis, Biomed. Environ. Mass Spectrom. 1989, 18, 673.

[7] A.J. Borgerding, R.A. Hites, Anal. Chem. 1992, 64, 1449

[8] J.A. Field, L.B. Barber, E.M. Thurman, B.L. Moore, D.L. Lawrence, D.A. Peake, Environ. Sci. Technol. 1992, 26, 1140.

[9] J.R. Simms, T. Keough, S.R. Ward, B.L. Moore, M.M. Bandurraga, Anal. Chem. 1988, 60, 2613

[10] F. Ventura, J. Caizach, A. Figueras, I. Espalder, D. Fraisse, J. Rivera, Wat. Res. 1989, 23, 1191 .

[11] J.D. Wernery, D.A. Peake, Rapid Com. Mass Spectrom. 1989, 3, 396.

[12] I. Ferrer, E.T. Furlong, Environ. Sci. Technol. 2001, 35, 2583.

[13] M. Petrovic, D. Barcelo, Anal. Chem. 2000, 72, 4560 .

[14] J.C. Dunphy, D.G. Pessler, S.W. Morrall, K.A. Evans, D.A. Robaugh, G. Fujimoto, A. Negahban, Environ. Sci. Technol. 2001, $35,1223$.

[15] C. Wegner, M. Hamburger, Environ. Sci. Technol. 2002, 36, 3250

[16] D.Y. Shang, R.W. Macdonald, M.G Ikonomou, Environ. Sci. Technol. 1991, 33, 1366.

[17] S.R. Corsi, D.H. Zitomer, J.A. Field, D.A Cancilla, Environ. Sci. Technol. 2003, in press.

[18] S.R. Corsi, D.W. Hall, S.W. Geis, Environ Tox. Chem. 2001, 20, 1483.

[19] C.A. Moody, J.A. Field, Environ. Sci. Technol. 1999, 33, 2800

[20] C.A. Moody, J.A. Field, Environ. Sci. Technol. 2000, 34, 3864.

[21] C.A. Moody, J.W. Martin, W.C. Kwan, D.C.G. Muir, S.A. Mabury, Environ. Sci. Technol. 2002, 36, 545

[22] M. Pabon, J.M. Corpart, C.A.L. Atofina, J. Fluorine Chem. 2002, 114, 149-156.

[23] C.A. Simenstad, J.R. Cordell, L. Tear, L.A. Weitkamp, F.L. Paveglio, K.M. Kilbride, K.L. Fresh, C.E. Grue, Environ. Tox. Chem. 1996, 15, 969
[24] F.L. Paveglio, K.M. Kilbride, C.E. Grue, C.A. Simenstad, K.L. Fresh, Environ. Tox. Chem. 1996, 15, 961.

[25] M.M. Schultz, D.F. Barofsky, J.A. Field, in 'Proceedings of the 50th ASMS Conference on Mass Spectrometry and Allied Topics', Orlando, Florida, 2002.

[26] M.M. Schultz, D.A. Griffin, C.A. Moody, S.A. Mabury, D.F. Barofsky, J.A. Field, in 'Proceedings of the Society of the $51^{\text {st }}$ ASMS Conference on Mass Spectrometry and Allied Topics', Montreal, Quebec, Canada, 2001.

[27] M.M. Schultz, D.F. Barofsky, J.A. Field, J. Environ. Eng. Sci., 2003, 20, 487-5011.

[28] E. Kissa, 'Fluorinated Surfactants and Repellants', Marcel Dekker, Inc., New York, 2001

[29] D.W. McLeese, V. Zitko, D.B. Sergeant, L. Burridge, C.D. Metcalfe, Chemosphere 1981, 10, 723

[30] K. Yoshimura, J. Am. Oil Chem. Soc. 1986, 63, 1590.

[31] S. Jobling, T. Reynolds, R. White, M. Parker, J. Sumpter, Environ. Health Perspec. 1995, 103, 582.

[32] S. Jobling, D. Sheahan, J.A. Osborne, P. Matthiessen, J.P. Sumpter, Environ. Tox. Chem. 1996, 15, 194

[33] C.M. Lye, D.L.J. Frid, M.E. Gill, D.W Cooper, D.M. Jones, Environ. Sci. Technol. 1999, 33, 1009.

[34] S. Jobling, J.P. Sumpter, Aquatic Toxicology 1993, 27, 361 .

[35] R. White, S. Jobling, S. Hoare, J. Sumpter, M. Parker, Endocrinology 1994, 135, 175.

[36] J.P. Giesy, K. Kannan, Environ. Sci. Technol. 2002, 36, 147A

[37] C.A. Moody, E.T. Furlong, G.N. Hebert, M.A. Odom, S.H. Strauss, J.A. Field, in 'Society of Environmental Toxicology and Chemistry: Sustaining Global Environmental Integrity', p. 123, Philadelphia, PA, 1999.

[38] C.A. Moody, G.N. Hebert, S.H. Strauss, J.A. Field, J. Environ. Monitor. 2003, 5, 341-345. 